\title{
Development of Hematopoietic Stem Cell Activity in the Mouse Embryo
}

\author{
Albrecht M. Müller, ${ }^{*}$ Alexander Medvinsky, ${ }^{\dagger}$ \\ John Strouboulis, † Frank Grosveld, $\neq$ \\ and Elaine Dzierzak ${ }^{\dagger}$ \\ tLaboratory of Gene Structure and Expression \\ Medical Research Council \\ National Institute for Medical Research \\ The Ridgeway, Mill Hill \\ London, NW7 1AA \\ England
}

\section{Summary}

The precise time of appearance of the first hematopoietic stem cell activity in the developing mouse embryo is unknown. Recently the aorta-gonad-mesonephros region of the developing mouse embryo has been shown to possess hematopoietic colony-forming activity (CFU-S) in irradiated recipient mice. To determine whether the mouse embryo possesses definitive hematopoietic stem cell activity in the analogous AGM region and to determine the order of appearance of stem cells in the yolk sac, AGM region, and liver, we transferred these embryonic tissues into adult irradiated recipients. We report here the long-term, complete, and functional hematopoietic repopulation of primary and serial recipients with AGM-derived cells. We observe potent hematopoietic stem cell activity in the AGM region before the appearance of yolk sac and liver stem cell activity and discuss a model for the maturation of stem cell activity in mouse embryogenesis.

\section{Introduction}

Hematopoietic cell development begins in the mouse embryo at approximately day 7 of gestation and is thought to originate in the yolk sac and proceed to the fetal liver before becoming resident in the adult bone marrow. The first visible differentiated hematopoietic cells in the conceptus are of the erythroid lineage. They appear in the 7.5 day post coitum (dpc) yolk sac (Russell and Bernstein, 1966; Russell, 1979) and later at $9 \mathrm{dpc}$, in the fetal liver (Johnson and Jones, 1973; Houssaint, 1981). Committed multilineage progenitors, colony-forming unit-culture (CFU-C), for erythroid and myeloid lineages have been reported in in vitro cultures of yolk sac as early as 7-8 dpc (Moore and Metcalf, 1970; Johnson and Barker, 1985; Wong et al. 1986). Fetal liver was also found to produce committed myeloid precursors at $9 \mathrm{dpc}$ and onwards (Moore and Metcalf, 1970; Samoylina et al., 1992). In multilineage (erythroidmyeloid) in vivo progenitor assays, colony-forming unitspleen (CFU-S) activity has been reported in $8 \mathrm{dpc}$ yolk sac

\footnotetext{
*Present address: Max Planck Institut für Immunbiologie, Stübeweg 51, 79108 Freiburg, Federal Republic of Germany

†Present address: Erasmus University, Department of Cell Biology and Genetics, 3000 DR Rotterdam, The Netherlands
}

(Moore and Metcalf, 1970), although many investigators have been unable to detect such activity until $9 \mathrm{dpc}$ (Perah and Feldman, 1977; Symann et al., 1978; Samoylina et al., 1990; Medvinsky, 1993). Recently, the aorta-gonadmesonephros (AGM) region of the embryo has been demonstrated to be a novel site of hematopoiesis in the mouse embryo and to contain CFU-S (erythroid-myeloid) progenitors beginning at $9 \mathrm{dpc}$ (Medvinsky et al., 1993). Progenitor activities in the AGM, yolk sac, and fetal liver were compared for the production of in vivo macroscopic colonies on the spleen at 8 days (CFU-S ${ }_{8}$ ) and 11 days (CFU$S_{11}$ ) posttransplantation. The first statistically significant $\mathrm{CFU}_{-S_{B}}$ progenitors appear at the 24 somite pair stage concurrently in the embryo body and the yolk sac. Both the number and frequency of CFU-S progenitors in the AGM region surpasses that of yolk sac and peaks in the 38-40 somite pair stage of the $10 \mathrm{dpc}$ embryo. This activity reaches a maximum in the AGM region just before the activity can be found in the fetal liver, suggesting that the AGM region may be the source of liver multilineage progenitors. However, these assays are specific only for the myeloid and erythroid lineages, not the lymphoid lineages. Progenitors for $T$ lymphoid lineage cells have been found in the embryonic yolk sac beginning at 8-9 dpc using in vitro thymic organ cultures (Liu and Auerbach, 1991) or stromal cell cocultures (Palacios and Imhof, 1993). In vitro cocultures of yolk sac (Cumano et al., 1993; Palacios and Imhof, 1993; Huang et al., 1994), embryo body (Ogawa et al., 1988; Huang and Auerbach, 1993), and the splanchnopleuric mesoderm (Godin et al., 1993) with stromal cell lines that support the differentiation of $B$ lymphoid cells have demonstrated $B$ cell activity beginning as early as 8-9 dpc in these tissues. Thus, all hematopoietic lineages can be produced by early embryonic tissues. However, a common embryonic progenitor-stem cell for all these lineages cannot be examined using these assays.

The most stringent and reliable measure of pluripotential hematopoietic stem cell (HSC) activity has been through the generation of adult radiation chimeras. Complete and long-term hematopoietic repopulation of adult mice has previously been demonstrated for whole (Micklem et al., 1966) and stem cell-enriched (Spangrude et al., 1988) adult bone marrow and fetal liver (Jordan et al., 1990). In addition, pluripotential and long-term HSC activity has been observed from late $11 \mathrm{dpc}$ yolk sac, long term after transplantation into lethally irradiated mouse recipients (Moore and Metcalf, 1970; Huang and Auerbach, 1993). The reports of HSC activity in yolk sac at earlier times in mouse embryonic development are sparse either because the procedures used for the identification of such cells in vivo are technically difficult or because such activity is limited. While two groups failed to find HSC activity in $9 \mathrm{dpc}$ yolk sac (Sonoda et al, 1983; Harrison et al., 1979), two other groups have shown that such yolk sac activity prior to $11 \mathrm{dpc}$ can lead to the long-term high level repopulation of only the erythroid lineage (Toles et al., 1989) or low level lymphoid-restricted repopulation (Weissman et al., 
1977,1978 ). These cells were delivered transplacentally or to the yolk sac of the embryo. Thus, the onset and temporal expansion of pluripotential HSC activity (equivalent to the stem cell activity found in the adult bone marrow) in the early developing mouse embryo, particularly in the AGM region, is unknown and in the yolk sac is uncertain.

In birds, adult hematopoietic cells are derived from intrabody stem cells (Dieterlen-Lievre, 1975; Dieterlen-Lievre and Martin, 1981), which are thought to reside in the mesodermal region containing the dorsal aorta (Cormier and Dieterlen-Lievre, 1988). As shown in elegant grafting experiments between quail embryos and chick yolk sacs, intraembryonic cells but not those of the yolk sac contribute to the complete adult avian blood system. The amphibian system has an analogous intraembryonic site, which contributes adult hematopoietic stem cell activity (Turpen et al., 1981; Maeno et al., 1985). Since the analogous site in the developing mouse embryo has not been examined for adult repopulating HSC activity, we performed direct transplantation of mouse AGM cells into lethally irradiated mouse recipients to test for complete long-term repopulating potential. We report here the results of radiation chimeras produced with embryonic tissues of 8-11 dpc mouse embryos. We demonstrate the complete, multilineage, long-term repopulation of such mice with cells of the AGM region and observe potent $\mathrm{HSC}$ activity in this intraembryonic region prior to the detection of stem cell activity in the yolk sac and the fetal liver. These in vivo results, in combination with previous in vitro progenitor and CFU-S data, suggest a novel model for mammalian HSC maturation.

\section{Results}

\section{The AGM Region of Developing Mouse Embryo Contains Long-Term Repopulating Hematopoietic Cell Activity}

One criterion for the assessment of hematopoietic stem cell activity is the long-term engraftment of the blood system of recipient mice. It has been shown that clonal stabilization of stem cell-derived hematopoietic repopulation occurs only 4-6 months posttransplantation (Jordan and Lemischka, 1990). The ability of embryonic tissues, particularly AGM region cells, to contribute to the prolonged hematopoietic repopulation of lethally irradiated adults was tested using cells from genetically marked embryos. A $\beta$-globin transgene and the $Y$ chromosome sequences $Y-2$ and Sry were used in these studies as markers for donor embryonic cells. As shown in Figure 1, embryos could be generated such that the donor genetic markers would be present only in contributing embryonic cells and not in maternal blood cells (a potential source of contaminating engrafting cells). Heterozygous or homozygous males transgenic for the human $\beta$-globin locus were mated with nontransgenic females. Embryo body or AGM region cells, as well as yolk sac, liver, circulating, and body remnant cells were prepared from a pooled mixture of male/ female, transgenic/nontransgenic embryos at $8,9,10$, or $11 \mathrm{dpc}$ and intravenously injected as a single cell suspension into lethally irradiated female recipients. Tissues from
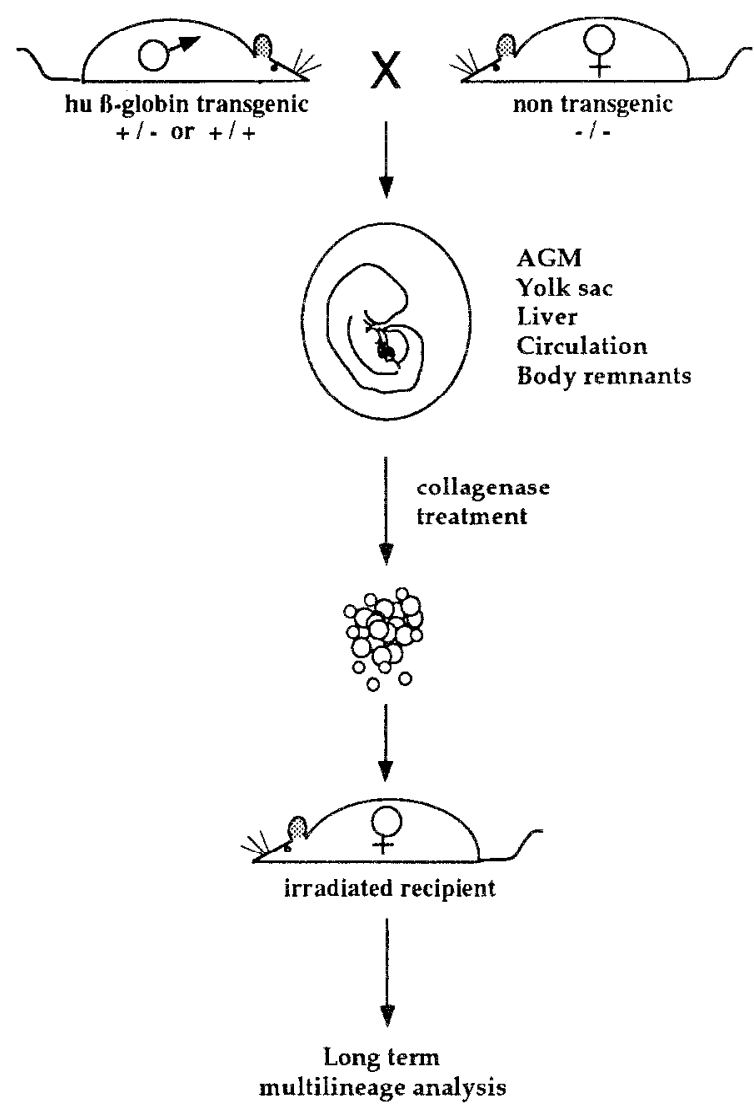

Figure 1. Strategy for the Generation of Genetically Marked Embryos and Injection of Embryonic Tissues into Recipients

To avoid contamination of embryonic tissues by maternal bloodderived hematopoietic progenitor cells, males heterozygous or homozygous for the human $\beta$-globin locus (Strouboulis et al., 1992) were used to produce genetically marked embryos. The embryonic tissues were dissected as described by Medvinsky et al. (1993), pooled, and collagenase-treated, and intravenously injected into lethally irradiated female recipient mice.

the individual embryos included in each experimental pool were typed (by polymerase chain reaction [PCR] or Southern blot) for the presence of the transgene or $Y$ chromosome marker so as to determine the percentage of marked cells injected. A limiting dose of unmarked syngeneic female bone marrow cells (Harrison, 1980) was also injected to aid the recipients in short-term survival following irradiation. Short-term and long-term repopulation analyses were performed on recipient peripheral blood DNA by PCR for the presence of the Sry male-specific gene.

As shown in Figure 2A, blood DNA samples from animals receiving the various embryonic tissues were negative $(<0.1 \%)$ for donor Sry signal when derived from 8 or $9 \mathrm{dpc}$ embryos. Only when $10 \mathrm{dpc}$ tissues (Figure 2B) or 11 dpc tissues (Figure 2C) were transplanted did recipients yield Sry-positive signal. Three animals receiving $10 \mathrm{dpc}$ AGM cells were Sry positive, while those receiving body remnant, circulating, or liver cells were negative. The 10 dpc AGM recipients were repopulated to varying degrees $(<0.1 \%$ to $>10 \%)$ at 1 month posttransplantation. At 3 months postinjection, engraftment persisted only in the 


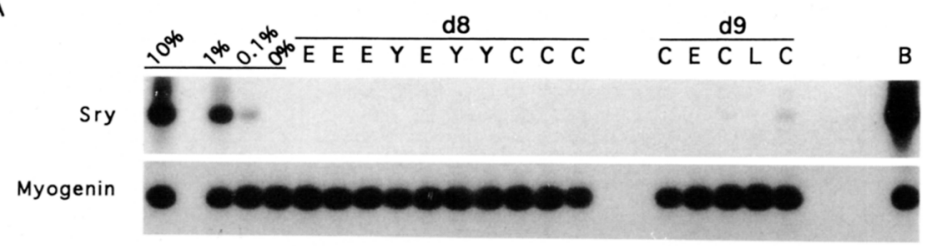

B
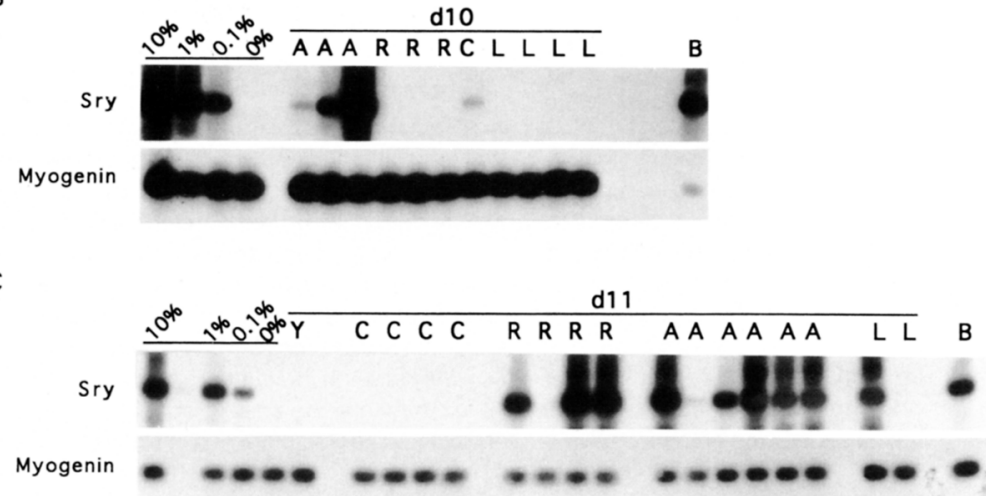

Figure 2. Temporal Analysis of Recipient Peripheral Blood after Injection of $8 \mathrm{dpc}$ through 11 dpc Embryonic Cells

Female recipients were injected with (A) 8 or $9 \mathrm{dpc},(\mathrm{B}) 10 \mathrm{dpc}$, and (C) $11 \mathrm{dpc}$ embryonic tissues generated from matings of heterozygous male $\beta$-globin transgenic mice. Peripheral blood was examined by PCR analysis a 3 months (for $8 \mathrm{dpc}$ recipients), 3.5 months (for $9 \mathrm{dpc}$ recipients), 1 month (for $10 \mathrm{dpc}$ recipients), and 3 months (for $11 \mathrm{dpc}$ recipients) posttransplantation. The embryonic tissues transplanted were the following: $(E)$, whole embryo; $(Y)$, yolk sac; (C), embryonic circulating cells; (L), fetal liver; (A). AGM; (R), body remnants; and $(B)$, control adult bone marrow. Autoradiograms of Southern blots after gel electrophoresis are shown. Filters were hybridized with Sry and myogenin (for DNA normalization) probes and the contribution standards were derived by diluting male into female genomic DNA. The two $<1 \%$ positive $10 \mathrm{dpc}$ AGM recipients lost their male Sry signal by 3 months posttransplantation. The third animal $>10 \%$ repopulated) is animal 9.2 shown in Figure 3A and is the predecessor of secondary and tertiary animals shown in Figure 6. All bone marrow control recipients were completely repopulated.
A

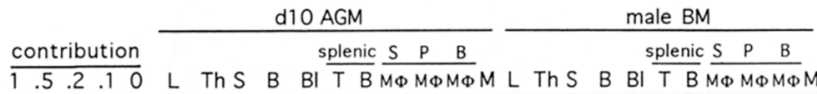

hurglobin $72-$

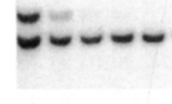

$\begin{array}{llllllllllll}0 & 0 & 0 & 0 & 0 * & 0 & 0 & 0 & 0 & 0 & 0\end{array}$

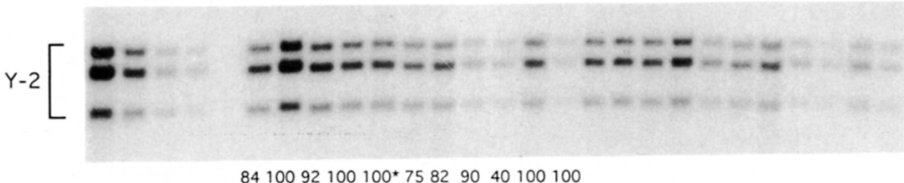

B

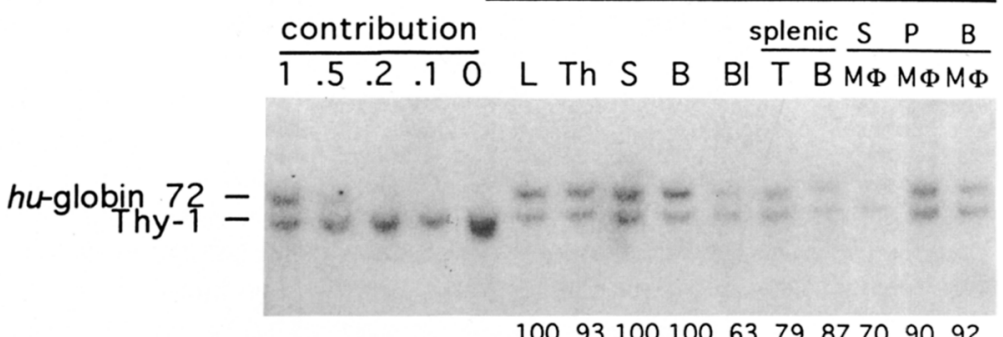

$1009310010063 \quad 7987709092$

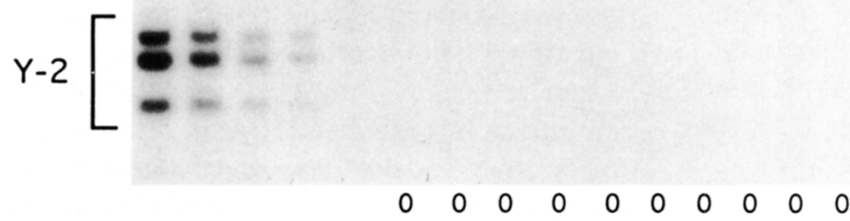

Figure 3. Multilineage Marker Analysis of the Long-Term 10 dpc AGM Repopulated 9.2 Mouse and B.2 Mouse

Recipient 9.2 (A) was sacrificed and analyzed at 7.5 months postinjection of one embryo equivalent $\left(1.8 \times 10^{4}\right) \mathrm{AGM}$ cells. Of the embryos used in this experiment, $50 \%$ were male as determined by Sry PCR. However, none of the embryos were positive for the globin transgene. Recipient B.2 (B) was sacrificed and analyzed at 8 months postinjection of one embryo equivalent $\left(3.7 \times 10^{4}\right.$ cells $)$ of AGM cells. Of the embryos used, $50 \%$ were male as determined by Sry PCR and all embryos were globin transgenic since a homozygous male was used for the mating. Recipient mouse DNAs were isolated from the following tissues: (L), lymph nodes; (Th), thymus; (S), spleen; (B), bone marrow; (BI), peripheral blood; (T), splenic T cells; (B), splenic B cells; (S), splenic macrophages; $(P)$ peritoneal macrophages; $(B)$, bone marrow macrophages; and $(M)$, bone marrow mast cells, cut with EcoRl, blotted as previously described (Strouboulis et al., 1992), and hybridized with the human globin and Thy-1 probes and rehybridized with a Y-2 probe. Contribution controls indicate $1,0.5$, $0.2,0.1$, and 0 copies of the globin transgene (12 kb hybridizing band) or copy equivalents of the $Y-2$ repetitive gene $(2.1,1.9$, and $1.5 \mathrm{~kb}$ hybridizing bands). The endogenous Thy-1 gene (8.2 kb hybridizing band) was used as a DNA normalization control. Quantitation of donor-derived repopulation was determined by densitometry and phosphorimaging and percentage of engraftment values are indicated under each lane. The value for peripheral blood repopulation $\left(^{*}\right)$ could not be determined accurately, since degradation of high molecular weight DNA took place during preparation of the sample. Tissue DNA samples from a transplanted adult bone marrow recipient are also shown. This female recipient was transplanted at the same time as the 9.2 mouse, received $4 \times 10^{6}$ male adult bone marrow cells, and was fully engrafted. 


\begin{tabular}{|c|c|c|c|c|}
\hline \multirow{2}{*}{$\begin{array}{l}\text { Embryo } \\
\text { age }\end{array}$} & \multirow{2}{*}{$\begin{array}{l}\text { Donor embryonic } \\
\text { tissues }\end{array}$} & \multirow{2}{*}{$\frac{\text { Number of positive recipients }}{\text { Number of recipients }}$} & \multirow{2}{*}{$\begin{array}{l}\text { Embryo equivalents } \\
\text { per recipient }\end{array}$} & \multirow{2}{*}{$\begin{array}{l}\text { Frequency o } \\
\text { repopulation }\end{array}$} \\
\hline & & & & \\
\hline \multirow[t]{4}{*}{ Day 10} & $112 \mathrm{AGM}$ & $3 / 96$ & 1.16 & $3 \%$ \\
\hline & 121 yolk sac & $0 / 74$ & 1.63 & $0 \%$ \\
\hline & 66 liver & $0 / 43$ & 1.53 & $0 \%$ \\
\hline & 33 circulation & $0 / 27$ & 1.22 & $0 \%$ \\
\hline \multirow[t]{4}{*}{ Day 11} & $18 \mathrm{AGM}$ & $11 / 19$ & 0.95 & $73 \%$ \\
\hline & 14 yolk sac & $10 / 17$ & 0.82 & $59 \%$ \\
\hline & 10 liver & $6 / 16$ & 0.67 & $40 \%$ \\
\hline & 13 circulation & $0 / 9$ & 1.45 & $0 \%$ \\
\hline
\end{tabular}

Embryonic tissues from 10 and 11 dpc were dissected and AGM, yolk sac, liver, and circulating cells were isolated. The number of donor embryonic tissues transplanted, the number of positive recipients out of the number of surviving transplant recipients, the average number of embryo equivalents per recipient, and the frequency of repopulation are indicated. Transplantation recipients were examined by Sry or human globin-specific PCR for the presence of donor male or transgenic cells in peripheral blood DNA at greater than 6 months postinjection. Each animal was independently analyzed at least two times and only animals with signal representing greater than $10 \%$ repopulation by donor cells are considered positive. Fourteen individual transplantation experiments were performed using $10 \mathrm{dpc}$ embryonic tissues and four individual transplantation experiments were performed using $11 \mathrm{dpc}$ tissues. Embryos were pooled before injection of single cell suspensions into female recipients. The number of cells in one embryo equivalent of AGM was 1.4-5 × $10^{4}$, yolk sac was 3-9.2 $\times 10^{4}$, liver was $0.9-6.7 \times 10^{4}$, and the circulation was $1-18 \times 10^{4}$. In four experiments with $10 \mathrm{dpc}$ tissues, one embryo equivalent was injected per recipient and in eight experiments, the embryo equivalents injected ranged from 9-0.03 per recipient. In two experiments with $11 \mathrm{dpc}$ tissues, one embryo equivalent was injected per recipient and in two experiments, the embryo equivalents injected ranged from 3-0.03 per recipient. A limiting number of normal, sygeneic female bone marrow (2 $\left.\times 10^{4}\right)$ or spleen $\left(2.5 \times 10^{5}\right)$ cells were coinjected to promote short-term survival of recipients. Only $50 \%$ of injected control animals survived, while all irradiation controls (no cells injected) died within 14 days. Each experiment also contained adult (male) bone marrow control recipients, which always tested positive for long-term complete engraftment.

The three positive recipients resulting from the injection of $10 \mathrm{dpc}$ AGM cells were derived from embryonic cells of the 39-41, 34-37, and 3435 somite pair stage and were further examined as shown in Figures 3 and 4 . The $11 \mathrm{dpc}$ embryonic tissues were obtained from embryos with $>42$ somite pairs.

high signal animal yielding $>10 \%$ donor repopulation (data not shown). Since this PCR assay was linear only to the $10 \%$ level, Southern blot analysis of the highly engrafted $10 \mathrm{dpc}$ AGM recipient demonstrated $100 \%$ repopulation (Figure $3 A)$. Also, the low level signal $(<0.1 \%)$ found in the $10 \mathrm{dpc}$ embryonic circulation transplanted animal was absent in this recipient when it was retested at 3 months posttransplantation. Thus, $10 \mathrm{dpc}$ AGM cells appear to be the most potent embryonic hematopoietic reconstituting cells when compared with other transplanted $10 \mathrm{dpc}$ embryonic cells. Interestingly, at $11 \mathrm{dpc}$ when other investigators have found high level repopulating activity in the yolk sac, we have found high level $(>10 \%)$ repopulation of recipients receiving $11 \mathrm{dpc} A \mathrm{AGM}$, body remnant, or liver cells (Figure $2 \mathrm{C}$ ). Thus, long-term repopulating activity is present in most embryonic tissues at $11 \mathrm{dpc}$.

\section{The Frequency of Long-Term Repopulating Hematopoietic Cell Activity in Developing Embryonic Tissues}

To establish more firmly the onset of AGM long-term hematopoietic repopulating activity compared with other embryonic tissues (particularly the yolk sac) and to examine further the frequencies of engraftment by the different embryonic tissues, we performed additional transplantation experiments. As shown in Table 1 at greater than 4 months posttransplantation of $10 \mathrm{dpc}$ tissues, 3 highly positive $>10 \%$ donor repopulated) recipients were obtained from the transplantation of 112 AGM regions into 96 recipients ( $\sim 1.16$ embryo equivalents per recipient). In contrast, when 121 yolk sacs or 66 livers were transplanted into 74 or 43 recipients (average of 1.63 and 1.53 embryo equivalents each), respectively, no mice were positive for the donor marker. Short term after transplantation we observed numerous low level donor positive recipients. Seven recipients receiving AGM cells and three recipients receiving yolk sac cells were found to be low level repopulated (between 1\% and 5\%) at 2 months but lost all donorderived cells when examined later. Only the three $10 \mathrm{dpc}$ AGM recipients originally testing $>10 \%$ donor positive remained positive long term after transplantation. These experiments suggest that the AGM region acquires detectable long-term high level repopulating activity at $10 \mathrm{dpc}$ (between the $\mathbf{3 4}$ and $\mathbf{4 1}$ somite pair stage) before yolk sac and liver and is limiting since only $3 \%$ of the recipients are high level engrafted.

When $11 \mathrm{dpc}$ AGM cells were transplanted ( $\sim 0.95 \mathrm{em}$ bryo equivalents per recipient), repopulation of recipients was found at a much higher frequency $(73 \%)$ than with $10 \mathrm{dpc}$ AGM cells. In addition, $11 \mathrm{dpc}$ yolk sac and liver cells were found to engraft long-term ( $\geqslant 3$ months) recipients to high levels $(>10 \%)$ and at high frequencies: $59 \%$ and $40 \%$, respectively (average of 0.82 and 0.67 embryo equivalents per recipient). No long-term repopulation was observed in recipients of 10 or $11 \mathrm{dpc}$ embryonic circulating cells. Thus, we have confirmed the high level repopulating frequency of day $\$ 1$ pc yolk sac cells seen by other investigators (Moore and Metcalf, 1970; Huang and Auerbach, 1993) and demonstrated that yolk sac is not the only day 11 embryonic tissue with high frequency stem cell activity; AGM region and liver are also highly active at this time in embryonic development. 
A

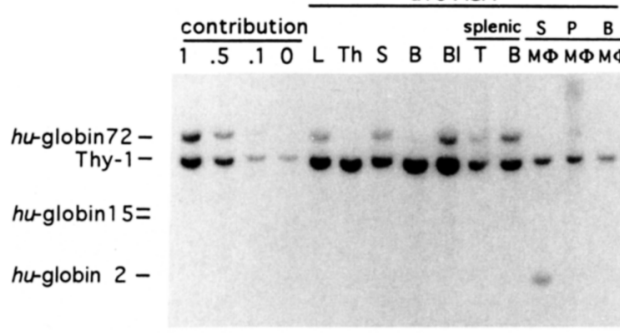

$39 \quad 0 \quad 46<3 \quad 54 \quad 42 \quad 67 \quad 70<100$

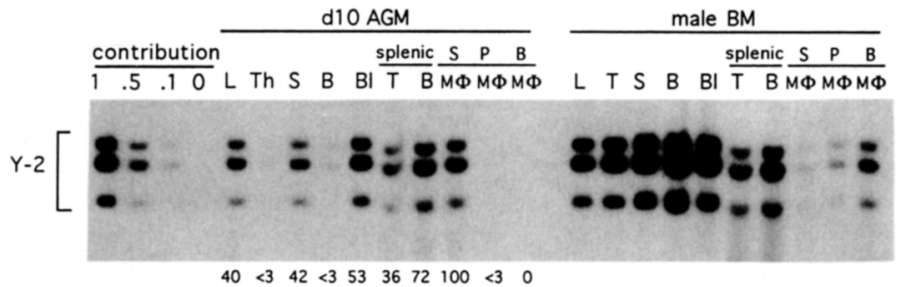

Figure 4. Multilineage Marker Analysis of the Long-Term Engrafted I.2 Mouse Injected with a Mixture of $10 \mathrm{dpc}$ Embryonic Cells

Recipient 1.2 was sacrificed and analyzed at 7 months postinjection of one embryo equivalent of a mix of AGM $\left(1.2 \times 10^{4}\right)$ cells from the 34-35 sp stage, liver $\left(0.96 \times 10^{4}\right)$ cells from the 32-35 sp stage, and yolk sac $\left(5 \times 10^{4}\right)$ cells from the 34-35 sp stage. Of the AGM cells used (total of 8 pooled embryos), $50 \%$ were derived from male embryos and $50 \%$ were globin transgene line 72 positive embryos. Of the liver cells used (total of 5 pooled embryos), $40 \%$ were derived from male embryos and $20 \%$ from globin transgene line 2 positive embryos. Of the yolk sac cells (total of 12 pooled embryos), $75 \%$ were derived from male embryos and $58 \%$ from globin transgene line 15 positive embryos. DNAs were isolated from hematopoietic tissues and enriched lineages, analyzed as described in Figure 3, and hybridized with human globin and Thy-1 probes (A) and then reprobed with a $Y$-2 fragment (B). Control lanes in (A)

demonstrate transgenic line-specific EcoRI integration fragments: lane 1, nontransgenic DNA; lane 2, DNA from a line 72 transgenic mouse; lane 3, DNA from a line 2 transgenic mouse; and lane 4, DNA from a line 15 transgenic mouse. Contribution controls indicate 1, 0.5, $0.2,0.1$, and 0 copies of the globin transgene or copy equivalents of the Y-2 repetitive gene. Quantitation of donor globin and $Y-2$ signal were performed by phosphorimaging and densitometry with the Thy-1 hybridization as a normalization control. The Thy-1 signal in the contribution controls varies due to the total amount of DNA per lane: lane 1, $10 \mu \mathrm{g}$ male DNA; lane 2, $5 \mu \mathrm{g}$ male DNA; lane $3,1 \mu \mathrm{g}$ male DNA; and lane $4,0.5 \mu \mathrm{g}$ female DNA. Percentage donor engraftment is indicated under each lane. Tissue DNA samples from an adult bone marrow recipient control are also shown in (B). This female recipient was transplanted at the same time as the 1.2 mouse, received $4 \times 10^{\mathrm{k}}$ male adult bone marrow cells, and was fully engrafted.

\section{Repopulation of AGM Recipient \\ Mice Is Multilineage}

A definitive characteristic of hematopoietic stem cell activity is the repopulation of all the mature blood lineages of the recipient. After the initial peripheral blood DNA PCR screening, we examined the extent of multilineage repopulation in the three positive primary recipients that recelved $10 \mathrm{dpc}$ AGM cells. Hematopoietic tissues (blood, thymus, spleen, and bone marrow) and specific cell lineages ( $B$ and $T$ cells, macrophages, and mast cells) were assayed by Southern blot analysis for the presence of the $Y$ chromosomal and the $\beta$-globin transgene markers. When males heterozygous for the transgene are used for the generation of donor embryos (see Figure 1), the two independently segregating markers ( $Y$ chromosome and globin transgene) should be individual in $25 \%$ and overlapping in $25 \%$ of the injected donor cells (total of $75 \%$ of donor cells are genetically marked).

Long-term engraftment of mouse 9.2 is shown in Figure $3 A$. This recipient, which received one embryo equivalent of AGM cells $\left(1.8 \times 10^{4}\right)$ from a pooled mixture of three male and three female embryos (all were nontransgenic and of the 39-41 somite pair stage) is highly repopulated in all the hematopoietic tissues and lymphoid and myeloid lineages at 7.5 months postinjection. The marked donorderived repopulating cells are male nontransgenlc cells as determined by hybridization with $Y$ chromosome ( $Y-2)$ and globin transgene-specific probes. Percentage of engraftment in each tissue and lineage varied and ranged from $40 \%-100 \%$ donor-derived cells as internally quantitated against Thy-1 endogenous gene hybridization. Thus, one embryo equivalent of AGM cells are capable of full and complete repopulation of a lethally irradiated adult recipient.

The $\mathrm{B} .2$ recipient mouse shown in Figure $3 \mathrm{~B}$ demonstrates reconstitution with one embryo equivalent of AGM cells (3.7 $\times 10^{4}$ cells) from a mixture of eight 34-37 somite pair embryos (four male, four female; eight transgenic). This animal is very highly engrafted in all hematopoietic tissues and lineages (macrophages and $B$ and $T$ lymphoid cells) at 8 months posttransplantation. Levels of engraftment ranged from $63 \%-100 \%$ in the hematopoietic tissues and $70 \%-92 \%$ in the enriched cultured lymphoid and myeloid lineages. These cells are derived from female transgenic-marked HSCs as determined by hybridization to the globin transgene probe (normalized by endogenous Thy-1 signal) and lack of signal with the $Y-2$ probe. The combined results of mouse 9.2 and B.2 demonstrate that neither genetic marker, $Y$ chromosome, nor globin transgene has an effect on the long-term multilineage engraftment of these recipients and suggest that one or very few AGM cells is capable of full and complete reconstitution.

A third positive recipient mouse, 1.2 is shown in Figure 4. This recipient received a mixture of embryonic cells (3235 somite pairs) to examine the competitive hematopoietic repopulation potential of AGM cells as compared with liver and yolk sac cells. The injected mixture of cells was derived from three separate globin transgenic lines with differing transgene chromosomal integration sites: AGM cells from line 72 , yolk sac cells from line 15 , and liver cells from line 2 . Thus, the origin of the repopulating cells in the recipient could be determined by EcoRI Southern blot analysis (Figure 4A, controls) for the unique fragments: a 12 kb fragment for line $72,5.3$ and $4.8 \mathrm{~kb}$ frag- 
ments for line 15 , and a $3.5 \mathrm{~kb}$ fragment for line 2 . High level engraftment $(36 \%-100 \%)$ is observed in most hematopoietic tissues and lineages as determined by globin transgene (Figure 4A) and $Y$-2 probe (Figure 4B) hybridizations. Three main patterns emerge from these blots. The first and predominating pattern shows equivalent signals for both the globin transgene and $Y \cdot 2$ markers in lymph node, spleen, blood, and splenic $B$ and $T$ cells. The hybridizing globin fragment migrates at $12 \mathrm{~kb}$ (line 72), indicating repopulation by AGM-derived cells. Thus, most hematopoietic cells are derived from male AGM cells. The second pattern is observed in a single lineage, the splenic macrophages of this recipient. These cells are male derived ( $Y$-2 positive) but do not carry the line 72 globin transgene marker. Instead, a globin hybridizing fragment migrating at $3.5 \mathrm{~kb}$ indicates splenic macrophage production from line 2, fetal liver cells. This marker is probably beneath the limits of detection in whole spleen DNA and suggests the presence of a low frequency long-term single lineage repopulating cell in $10 \mathrm{dpc}$ liver. The liver at this early stage of development has been found to be capable of producing macrophages on adult bone marrow stroma in Dexter-type cultures (A. M. and N. L. Samoylina, unpublished data). Finally, the third pattern is found in the bone marrow, thymus, and peritoneal and bone marrow macrophages. While no or faint globin (line 72) and $Y$-2 hybridizing signals are seen, it appears that most of these cells are derived from female nontransgenic cells and could be donor or endogenous in origin. Thus, this recipient is repopulated by at least three stem/progenitor cells. These results strongly suggest that in $10 \mathrm{dpc}$ hematopoietic tissues, the most competent cells for long-term high level multilineage hematopoietic engraftment under our stringent transplantation conditions are from the AGM region.

In addition, we have performed multilineage analysis on long-term donor-repopulated recipients receiving $11 \mathrm{dpc}$ AGM region, yolk sac, or liver cells. All three embryonic tissues were capable of high level repopulation of all hematopoietic tissues and lineages analyzed (data not shown).

\section{Functional Repopulation of the Erythroid Lineage in Long-Term Repopulated AGM Recipients}

While we have shown that AGM cells are capable of producing myeloid and lymphoid lineage cells in vivo, we sought to determine whether erythroid lineage cells are also produced. It was aiso of interest to determine whether AGM stem cell-derived erythroid cells would be capable of appropriate developmental expression of globin genes. The use of the complete human globin transgene locus allowed us to detect the presence of functional donorderived human globin in erythrocytes by S1 RNA analysis and to determine whether embryonic, fetal, and/or adult globins were being produced in the peripheral blood of AGM recipient mice (Figure 5). When tested at 8 months posttransplantation, the peripheral blood of one out of two animals receiving $10 \mathrm{dpc} A G M$ cells was found to be highly positive for adult human $\beta$-globin expression (Figure 5 , lanes 4 and 5 ). No human $\varepsilon$ or $\gamma$-globin expression was observed. The positive $10 \mathrm{dpc}$ AGM recipient was the $B .2$ mouse, described in Figure 3B. When quantitative expres-

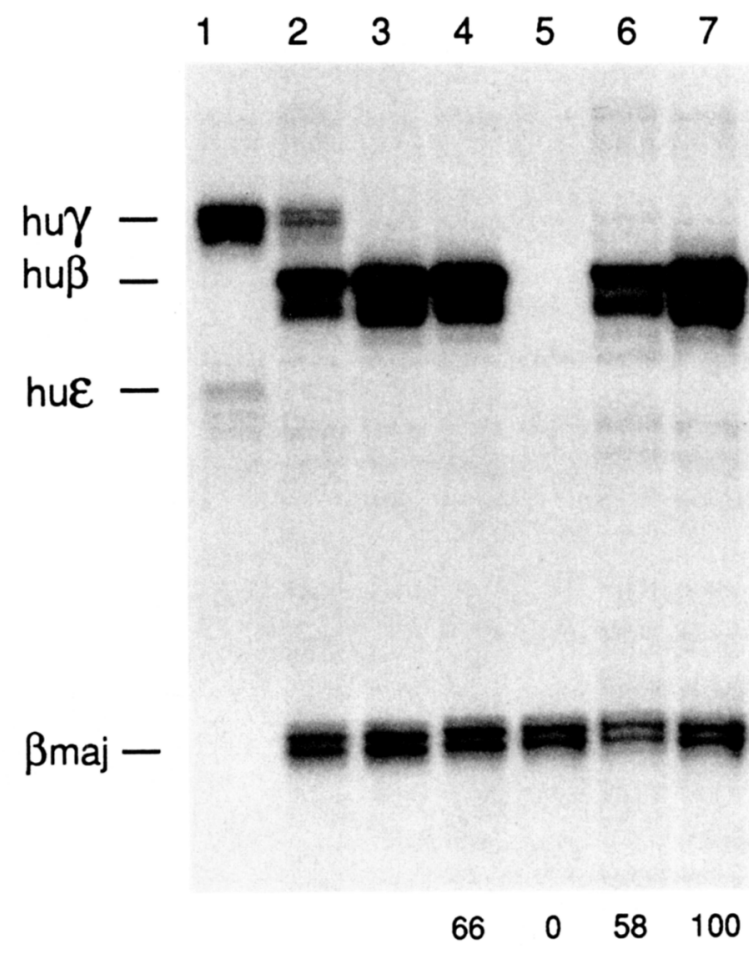

Figure 5. Expression of the Human $\varepsilon, \gamma$, and $\beta$ Transgenes in the Peripheral Blood of AGM Transplantion Recipients by S1 Nuclease Protection Analysis

S1 nuclease protection was performed with probes specific for human $\gamma \sim \beta-$, and $\varepsilon$-globin transgene RNAs and endogenous mouse $\beta$ major globin RNA (erythroid lineage control). Protected fragments are indicated at left. RNA samples protected in each lane are as follows: lane $1,10 \mathrm{dpc}$ line 72 transgenic yolk sac RNA (38 somite pairs); lane 2, 12 dpc line 72 transgenic fetal tiver RNA; lane 3 , line 72 transgenic adult spleen RNA; lanes 4 and 5, peripheral blood RNA from two animals injected with line 72 transgenic (34-37 somite pain) $10 \mathrm{dpc}$ AGM cells at 8 months posttransplantation; lane 6 , peripheral blood RNA from an animal injected with (44 somite pair) $11 \mathrm{dpc}$ AGM cells at approximately 2 months posttransplantation; lane 7, peripheral blood RNA from an animal injected with human globin transgenic adult bone marrow at approximately 2 months posttransplantation. Quantitation of expression levels of human $\beta$-globin transgene (indicated beneath each sample lane) were performed by densitometry using mouse $\beta$ major expression as an internal control. Since the expression of this transgene is known to be copy number-dependent (Strouboulis et al., 1992), $100 \%$ expression indicates the level of a single copy of the human $\beta$-globin transgene compared with the diploid level expression of the endogenous mouse $\beta$ major gene. The peripheral blood ANA sample in lane 4 is from the $B .2$ recipient shown in Figure $3 B$.

sion of the human $\beta$-globin transgene of the peripheral blood of the B. 2 mouse was compared with that of a fully engrafted bone marrow control recipient $(100 \%$ expression), human $\beta$-globin RNA was produced to the $66 \%$ level (66\% of the B.2 blood cells produce RNA to the level expected of this single copy transgene; see Strouboulis et al., 1992). This level is consistent with the percentage of engraftment $(63 \%)$ determined by DNA analysis of $B .2$ peripheral blood (Figure $3 B$ ). In addition, a recipient receiving $11 \mathrm{dpc}$ AGM cells was found to express human $\beta$-globin at 2 months postinjection (Figure 5, lane 6). In this recipient, as well as numerous other recipients, the level of hu- 


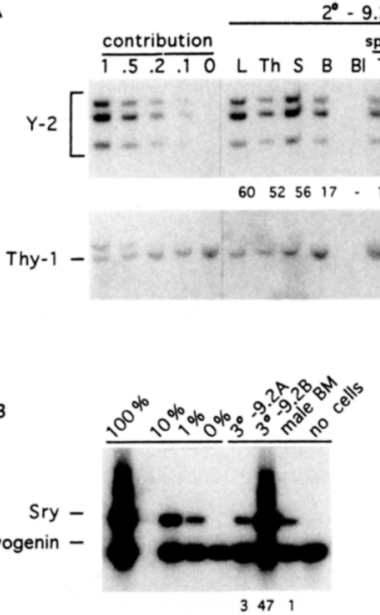

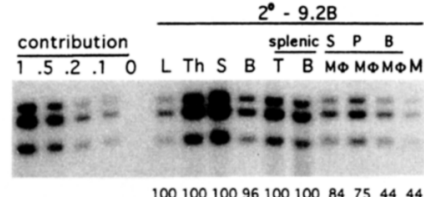

1001001009610010084754444

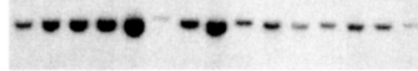

ripheral blood DNA (minus) was obtained for recipient $9.2 A$ and the percentage engraftment recipients was low due to fibroblast overgrowth in the culture.

(B) PCR analysis of peripheral blood DNA from tertiary recipients 7 weeks after injection of $3 \times 10^{6}$ bone marrow cells from secondary transplant mice 9.2A and 9.2B. Contribution controls indicate $100 \%, 10 \%, 1 \%$, and $0 \%$ Sry signal, with myogenin as the normalization standard. The lane marked male BM and no cells indicates peripheral blood DNA obtained from recipients at 7 weeks posttransplantation of $4 \times 10^{6}$ male bone marrow cells or $2.5 \times 10^{5}$ female spleen cells, respectively. Quantitation was performed by densitometry and percentage engraftment indicated under sample lanes.

man $\beta$-globin expression in peripheral blood was found to correspond to the level of engraftment when DNA analysis was performed (data not shown). Thus, repopulation in the erythroid lineage with genetically marked cells, in addition to the repopulation shown in the myeloid and lymphoid lineages, indicates the presence of multilineage repopulating cells in the AGM reglon of the embryo.

\section{Serial Transplantation of AGM-Derived Cells} Results in Long-Term Multilineage Repopulation The most stringent test for the presence of long-term selfrenewing stem cell activity in the AGM region is the serial transplantation of bone marrow from the primary recipients into secondary recipients for long-term multilineage repopulation. Such transplantation was performed at 8 months postengraftment of mouse 9.2 (Figure $3 A$ ). Initially, the CFU-S 11 activity of the donor cells was measured and resulted in all colonies positive for the $\mathrm{Y}-2$ sequence (data not shown). Long-term repopulation of secondary recipients was also tested by transplantation of bone marrow cells $\left(3 \times 10^{6}\right)$ from primary recipient 9.2 into lethally irradiated adult recipients. As shown in Figure $6 \mathrm{~A}$, all hematopoietic tissues and lineages of two secondary recipients, $9.2 \mathrm{~A}$ and $9.2 \mathrm{~B}$, were repopulated with donor marked cells at 4 months posttransplantation. Hematopoietic tissue and lineage engraftment of animal 9.2A ranged from $12 \%-86 \%$, while that of animal $9.2 \mathrm{~B}$ ranged from $44 \%-100 \%$. When bone marrow cells $\left(3 \times 10^{6}\right)$ from secondary animals $9.2 \mathrm{~A}$ and $9.2 \mathrm{~B}$ were transplanted into tertiary recipients (Figure $6 \mathrm{~B}$ ), again repopulation was observed. The $9.2 B$ bone marrow contributed to $47 \%$ repopulation of peripheral blood-nucleated cells and 9.2A bone marrow contributed to $3 \%$ repopulation at 7 weeks posttranplantation as determined by Sry-specific PCR. These data indicate that AGM-derived hematopoietic cell activity can be serially transplanted and that the level of engraftment of the long-term secondary recipients corresponds well to the percentage of donor-derived cells in the bone marrow of the primary recipient (see Figure 3A).

\section{Discussion}

While previous investigations have lead to the general acceptance that the yolk sac functions as the primary and only site of hematopoiesis in the early $(11 \mathrm{dpc}$ ) developing mouse embyo (Moore and Metcalf, 1970; Tavassoli, 1994; Huang et al., 1994), we have found the presence of potent and high frequency HSC activity in the AGM region, as well as the liver and the yolk sac. We have shown that the AGM-derived hematopoietic cells bear all the hallmark characteristics of adult bone marrow HSCs: long-term persistent engraftment, high level repopulation of all hematopoietic lineages, and the ability to repopulate secondary and tertiary recipients serially. In the $11 \mathrm{dpc}$ AGM region, this HSC activity appears at a higher frequency than in liver or yolk sac. Earlier in development, at $10 \mathrm{dpc}$, we observed HSC activity only in the AGM region. Since only $3 \%$ of AGM recipients were engrafted, long-term high level repopulation was limiting, probably reflecting repopulation by as few as one HSC. Although we cannot exclude the possibility that HSCs exist at a low frequency in $10 \mathrm{dpc}$ yolk sac and liver, these data favor the AGM region as the initial source of long-term repopulating cells and suggest that AGM HSCs may migrate to the fetal liver as well as the yolk sac by $11 \mathrm{dpc}$ (Medvinsky, 1993). Alternatively, AGM HSCs may not be produced in situ, but this region may give competence to, maintain, or expand stem cells migrating from other sites such as the yolk sac. Interestingly, the AGM region is a site of stem cell factor and the c-kit receptor expression at $10 \mathrm{dpc}$ (Matsui et al., 1990; 


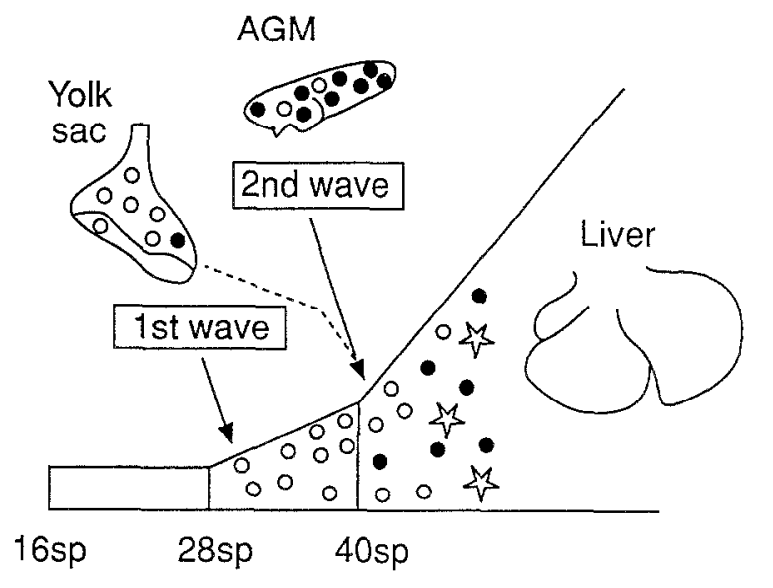

$$
\begin{aligned}
& \text { - - committed precursors } \\
& \text {-CFU-S } \\
& \$ \text { - repopulating activity }
\end{aligned}
$$

Figure 7. Proposed Waves of Hematopoietic Activity Entering the Fetal Liver during Embryonic Development

Representation of the putative sources of origin and temporal emergence of various measureable hematopoietic activities in the liver rudiment. Waves of hematopoietic activity in the yolk sac and the AGM region always precede the onset of committed precursor, CFU-S, and repopulating activities in the liver and predict a role for these embryonic tissues in establishment of fetal liver hematopoiesis.

Keshet et al., 1991). This ligand and receptor are known to play a role in primordial germ cell expansion (Godin et al., 1991; Dolci et al., 1991), hematopoiesis (Russell, 1979), and CFU-S production (Witte, 1990).

Surprisingly, we found that HSC activity in the embryo develops at a relatively late time in gestation $(10 \mathrm{dpc})$ as compared with the appearance of the first differentiated hematopoietic cells in the embryonic yolk sac at $7.5 \mathrm{dpc}$, the first CFU-C progenitors at $8 \mathrm{dpc}$, and the first CFU-S progenitors at $9 \mathrm{dpc}$. Although slightly later in developmental time, these different hematopoietic cell types are found in the developing liver rudiment in the identical sequence (reviewed by Medvinsky, 1993). Previously, migration of hematopioetic cells from the yolk sac to the fetal liver has been strongly suggested (Johnson and Moore, 1975; Cuddenec et al., 1981; Houssaint, 1981). This, in combination with the various hematopoietic cell types arising in the yolk sac, AGM region, or both, is suggestive of waves of hematopoietic activity emerging in the fetal liver. As shown in Figure 7, committed precursors (CFU-C) arising in the yolk sac could be responsible for the first wave of hematopoietic activity observed in the liver at the 28 somite pair stage. Later in the second wave, CFU-S activity primarily from the AGM region could contribute to the appearance of CFU-S in the liver at the 40 somite pair stage. Finally, HSCs from the AGM region could contribute to stem cell activity in the liver at $11 \mathrm{dpc}$. Precedence for waves of hematopoietic activity has been previously established in the colonization of the avian thymus (Coltey et al., 1987, 1989).

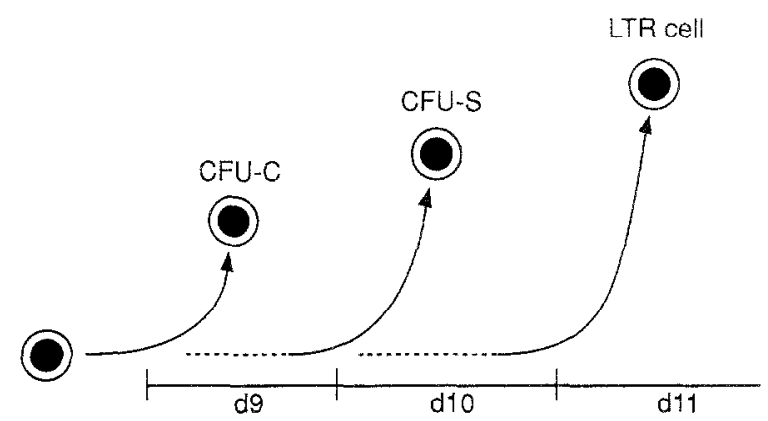

Figure 8. Model of Hematopoietic Stem Cell Maturation The kinetic appearance of various hematopoietic activities in the early developing mouse embryo is shown. Long-term repopulating (LTR) activity is observable in the mouse embryo only at late $10 \mathrm{dpc}$, while CFU-C and CFU-S activity generally appear at 8 and $9 \mathrm{dpc}$, respectively. This could suggest a sequence in which a more primitive embry. onic cell(s) is first capable of only committed activity to differentiated hematopoietic cells, then acquires the ability to form progenitor cells for CFU-S activity, and only later matures to full competence to become a multilineage long-term repopulating HSC. Alternatively, this sequence of appearance could be the result of low cell number or limits of detection of individual assays. In addition, it is unknown whether these functional hematopoletic activities are directly related through the progeny of a single cell or are independently established as indicated by the dotted lines.

How is it then that differentiated hematopoietic cells, committed progenitors, and CFU-S progenitors appear in the mouse embryo before long-term repopulating cells? Unlike the adult hematopoietic system, in which the classical hierarchical scheme illustrates stem cell to CFU-S progenitor to committed cell to differentiated cell production, these activities appear to develop in the reverse order in the embryo (Figure 8 ). Our observation that stem cell activity does not develop until $10 \mathrm{dpc}$ raises a number of interesting possibilities: embryonic HSCs cannot functionally repopulate adult recipients; the frequency of the longterm repopulating cell in the early embryo compared with the committed progenitors is initially low and undetectable because of seeding inefficiency in the transplant recipients; embryonic HSCs are intrinsically programmed to produce large numbers of differentiated cells, then committed progenitors, and finally adult repopulating HSCs in this sequence; specific microenvironments direct a small number or pool of prestem or stem cells to various activities. In early developing yolk sac, they are directed to the formation of differentiated hematopoietic cells and only later, when other growth factors/receptors or microenvironments (intraembryonic) become available can intermediate progenitors (CFU-S) develop. Finally, definitive stem cell potential is acquired only after competency factors/ specific microenvironments (for example, expansion or self-renewal) become available in the embryo.

These scenarios cannot be distinguished at the present time, nor can the number of initial prestem or stem cells be determined. We are presently establishing organ culture and stromal coculture systems along with clonal retroviral marking of 9, 10, and $11 \mathrm{dpc}$ AGM region, yolk sac, and liver to address these questions. Also, the lineage relationship of the stem/prestem cells involved in produc- 
tion of the various embryonic hematopoietic activities cannot be determined. Various cell surface markers, Sca-1, AA4.1, and Thy-1 have been described for HSCs of the adult mouse bone marrow and fetal liver. Recent studies by Huang et al. (1994) have shown that unlike fetal and adult HSCs, yolk sac cells from late day 10 embryos express AA4. 1 but not Sca-1. We have performed preliminary reverse transcriptase-PCR analysis of RNA from $10 \mathrm{dpc}$ embryonic tissues using primers specific for the Sca-1 gene (Ly-6A/E) and have found high expression in the AGM region and only very low expression in the yolk sac. We are presently attempting to enrich for HSCs from the AGM region using the Sca-1 and AA4.1 antibodies. It would be very interesting if AGM cells expressed both markers, perhaps indicating a more developmentally advanced stem cell phenotype. This marker could be extremely useful in determining the sequence of events (for example, expansion or migration) leading to the development of functional HSCs in the mouse embryo.

\section{Experimental Procedures}

\section{Cell Preparations}

(CBA $\times$ C57BL10)F 1 females were bred with transgenic heterozygous or homozygous males for the human globin gene (Strouboulis et al., 1992). The appearance of the vaginal plug was designated as day 0 . Embryos were aseptically removed from uteri and dissected with tungsten needles in L-15 medium (Flow Lab) with $5 \%$ fetal calf serum under the dlssectlon microscope. Indlvidual embryonic tissues were further dispersed with the use of tungsten needles and then incubated for $1-1.5 \mathrm{hr}$ in $0.1 \%$ collagenase with $10 \%$ fetal calf serum at $37^{\circ} \mathrm{C}$. After gentle pipetting and washing, cells were injected intravenously in the tail vein of 2- to 3-month-old irradiated (CBA $\times$ C57BL) 10)F1 female mice. The recipients were exposed to a split dose of 1000 rads of a ${ }^{\circ 0} \mathrm{Co}$ source. The embryo tissue cells were coinjected with either $2 \times 10^{4}$ female bone marrow cells or with $2.5 \times 10^{5}$ adult female splenocytes for immediate short-term radiation protection. These doses were limiting for long-term survival, as we found that about $50 \%$ of control-injected animals died within 2 months. All noninjected irradiation control mice died within 14 days. Mice were housed in positive pressure cabinets and received neomycin $(0.16 \mathrm{~g} / 100 \mathrm{ml})$ in their drinking water for the first 4 weeks following the irradiation. All animals were obtained from the specific pathogen-free breeding facility at the National Institute for Medical Research, London, and all animal procedures were in accordance with the Animals Scientific Procedures Act, 1986, United Kingdom.

\section{DNA Preparation, PCR, and Southern Blot Analysis}

Whole genomic DNA was isolated from the peripheral blood and tissues of recipient animals by proteinase $\mathrm{K}$ digestion, phenol-chloroform extraction, and isopropanol precipitation as described in Maniatis et al. (1982). Positive displacement pipettes or filter tips were used and reagents and materials were specially handled for utilization in PCR. The PCR reaction was done as follows: $200 \mathrm{ng}$ of genomic DNA was added to a mixture containing $1 \mathrm{U}$ Taq polymerase (Biotaq), PCR buffer (Biotaq), PCR primers (100 $\mathrm{ng}$ each), and $0.2 \mathrm{mM}$ nucleotides (Perkin-Elmer Cetus). The sequences of the PCR primers are as follows: Sry primers, 5'-TCA TGA GAC TGC CAA CCA CAG-3' and 5'-CAT GAC CAC CAC CAC CAC CAA-3' (Koopman et al., 1991); myogenin primers, 5'-TTA CGT CCA TCG TGG ACA GC-3' and 5'-TGG GCT GGG TGT TAG TCT TA-3'; and the human $\beta$-globin primers 5 '-CTT CAG GTT CCC AGT GAG GAT G-3' and 5'-GCT CCC TAA GGG GTA AAG AGT G-3'. The reactions for the combination Sry-myogenin PCA were initially heated at $94^{\circ} \mathrm{C}$ for $10 \mathrm{~min}$, followed by $26-33$ cycles of $94^{\circ} \mathrm{C}$ for $10 \mathrm{~s}, 65^{\circ} \mathrm{C}$ for $30 \mathrm{~s}$, followed $10 \mathrm{~min}$ at $72^{\circ} \mathrm{C}$; the cycle parameter for the human $\beta$-globin and myogenin primers was $94^{\circ} \mathrm{C}$ for $10 \mathrm{~s}, 26-33$ cycles of $94^{\circ} \mathrm{C}$ for $10 \mathrm{~s}, 55^{\circ} \mathrm{C}$ for $30 \mathrm{~s}, 72^{\circ} \mathrm{C}$ for $1 \mathrm{~min}$, followed by $10 \mathrm{~min}$ at $72^{\circ} \mathrm{C}$. The cycles were done in a Techne PHC-2 thermocycler. The sizes of the amplified PCR products are $441 \mathrm{bp}$ (Sry), 428 bp (human $\beta$-globin), and 245 bp (myogenin). The products were separated on $1.5 \%$ agarose gels, transferred to nylon membranes, and hybrldized with an Sry-specific probe (p422, gift of J. Gubbay) and gel-purified myogenin, human $\beta$-globin fragments, or both after PCR amplification. A semilinear relationship was obtained between the amount of input $D N A$ and signal strength of the PCR product after quantitation by phosphorimage analysis (A. M. M. and E. D., 1993).

For genomic Southern blots, $5 \mu \mathrm{g}$ of genomic DNA were digested over night with EcoRl and separated on a 1\% agarose gel. After blotting, the filters were hybridized with a $3.3 \mathrm{~kb}$ EcoRI probe specific for the human $\beta$-globin transgene (Blom van Assendelft et al., 1989) and a $1.3 \mathrm{~kb}$ Apal Thy-1 gene fragment (Giguere et al., 1985). After exposure to $X$-ray film, the filter was stripped and reprobed with a $Y$ chromosome-specific probe ( $\rho$ Y-2, Lamar and Palmer, 1984). All probes were radioactively labeled by nick translation (Amersham). The percentage engraftment was determined by quantitation of radioactive fragments on a phosporimager (Molecular Dynamics), densitometer (Chromoscan 3) or both.

\section{In Vitro Cultures}

To expand and support the growth of $B$ cells, a single cell suspension from spleen was cultured in $10 \mu \mathrm{g} / \mathrm{ml}$ lipopolysaccharide (Sigma) in complete medium; to obtain splenic $T$ cells, spleen cells were grown in complete medium supplemented with 10-40 U/ml murine interleukin 2 (IL-2) (Biosource) and $5 \mu \mathrm{g} / \mathrm{ml}$ Concanavalin A (Sigma). Complete medium consists of RPMI 1640, 5\% FCS, $2 \mathrm{mM}$ L-Glutamine, $10 \mathrm{mM}$ HEPES, $10 \mathrm{U} / \mathrm{ml}$ penicillin, $10 \mu \mathrm{g} / \mathrm{ml}$ streptomycin, and $0.1 \mathrm{mM}$ 2-mercaptoethanol. Cells were cultured for $3-4$ days at $37^{\circ} \mathrm{C}$ and $5 \%$ $\mathrm{CO}_{2}$. After cell harvest, the identity of the cells was verified by fluorescence-activated cell sorter (FACS) analysis. At least $80 \%-90 \%$ of the cells grown under $\mathrm{T}$ cell growth condltions were Thy-1 positive. Of the splenocytes grown under B cell growth conditions, 80\%-90\% were positive for B220. Genomic DNA was prepared from the harvested cells and analyzed by PCR as described above.

Macrophages were obtained from the adherent cell fraction of peritoneal wash, bone marrow, or spleen cells and expanded in complete medium with 10\% L929-conditioned medium for 4-7 days. Cells were lysed directly on the tissue culture plate for DNA preparation. Bone marrow-derived mast cells were established from the nonadherent fraction of bone marrow cells. Cultures were maintained for a period of 4 weeks in RPMI 1640, 10\% FCS, nonessential amino acids, 40 $\mu \mathrm{M} \beta$-mercaptoethanol, $2 \mathrm{mM} \mathrm{L-Glutamine,} 10 \mathrm{U} / \mathrm{ml}$ penicillin, and $10-$ $20 \mathrm{U}$ of IL-3. Mast cells were identified by staining with May-Grünwald/ Giemsa dye.

\section{RNA Analysis}

Approximately $100 \mu$ l of peripheral blood was obtained from transplant recipients by tail vein nicking. Blood RNA was extracted with RNAzol $B$ (Cinna/Biotecx) and expression analysis of globin genes was carried out as described in Strouboulis et al. (1992); all S1 probes are as previously described (Kollias et al., 1986; Fraser et al., 1990; Lindenbaum and Grosveld, 1990). Quantitation was performed by densitometry using the mouse $\beta$ major signal as an RNA normalization control and human $\beta$-globin signal in Figure 6 , lane 7 as the $100 \%$ expression control.

\section{Acknowledgments}

The authors would like to thank C. Miles, B. Daly, Dr. J. Ellis, and $S$. Jenkins for assistance in various aspects of this work. We also acknowledge the productive discussions with other members of the lab and with Dr. I. Lemischka. We thank Drs. R. Mulligan, P. Rigby, and $V$. Tybulewicz for critical reviews of the manuscript. This work was supported by an European Molecular Biology Organization Fetlowship to A. M. M., a Royal Society Fellowship to A. M., the Howard Hughes Medical Institute, and the Medical Research Council, United Kingdom.

Received April 27, 1994; revised May 13, 1994. 


\section{References}

Blom van Assendelft, G., Hanscombe, O., Grosveld, F., and Greaves, D. R. (1989). The $\beta$-globin dominant control region activates homologous and heterologous promoters in a tissue-specific manner. Cell $56,969-977$.

Coltey, M., Jotereau, F. V., and Le Douarin, N. M. (1987). Evidence for a cyclic renewal of lymphocyte precursor cells in the embryonic chick thymus. Cell Differ. 22, 71-82.

Coltey, M., Bucy, R. P., Chen, C. H., Cihak, J., Losch, U., Char, D., Le Douarin, N. M., and Cooper, M. D. (1989). Analysis of the first two waves of thymus homing stem cells and their $T$ cell progeny in chick-quail chimeras. J. Exp. Med. 170, 543-557.

Cormier, F., and Dieterlen-Lievre, F. (1988). The wall of the chick embryo aorta harbours M-CFC, G-CFC, GM-CFC and BFU-E. Development 102, 279-285.

Cuddenec, C. A., Thiery, J.-P., and Le Douarin, N. M. (1981). In vitro induction of adult erythropoiesis in early mouse yolk sac. Proc. Natl. Acad. Sci. USA 78, 2412-2415.

Cumano, A., Furlonger, C., and Paige, C. J. (1993). Differentiation and characterization of B-cell precursors detected in the yolk sac and embryo body of embryos beginning at the 10- to 12-somite stage. Proc. Natl. Acad. Sci. USA 90, 6429-6433.

Dieterlen-Lievre, F. (1975). On the origin of haematopoietic stem cells in the avian embryo: an experimental approach. J. Embryol. Exp. Morphol. 33, 607-619.

Dieterlen-Lievre, F., and Martin, C. (1981). Diffuse intraembryonic hemopoiesis in normal and chimeric avian development. Dev. Biol. 88 , 180-191.

Dolci, S., Williams, D. E., Ernst, M. K., Resnick, J. L., Brannan, C. I., Lock, L. R., Lyman, S. D., Boswell, H. S., and Donovan, P. J. (1991). Requirement for mast cell growth factor for primordial germ cell survival in culture. Nature 352, 809-811.

Fraser, P., Hurst, J., Collis, P., and Grosveld, F. (1990). DNAasel hypersensitive sites 1,2 and 3 of the human $\beta$-globin dominant control region direct position-independent expression. Nucl. Acids Res. 18, 3503-3508.

Giguere, V., Isobe, K.-l., and Grosveld, F. (1985). Structure of the murine Thy-1 gene. EMBO J. 4, 2017-2024.

Godin, I., Deed, R., Cooke, J., Zsebo, K., Dexter, M., and Wylie, C. C. (1991). Effects of the steel gene product on mouse primordial germ cells in culture. Nature 352, 807-809.

Godin, I. E., Garcia-Porrero, J. A., Coutinho, A., Dieterlen-Lievre, F., and Marcos, M. A. R. (1993). Para-aortic splanchnopleura from early mouse embryos contains B1a cell progenitors. Nature $364,67-70$.

Harrison, D. E. (1980). Competitive repopulation: a new assay for longterm stem cell functional capacity. Blood 55, 77-81.

Harrison, D. E., Astle, C. M., and DeLaitre, J. A. (1979). Processing by the thymus is not required for cells that cure and populate W/W recipients. Blood 54, 1152-1157.

Houssaint, E. (1981). Differentiation of the mouse hepatic primordium II. Extrinsic origin of the hematopoietic cell line. Cell Diff. 10, 243252.

Huang, H., and Auerbach, R. (1993). Identification and characterization of hematopoietic stem cells from the yolk sac of the early mouse embryo. Proc. Natl. Acad. Sci. USA 90, 10110-10114.

Huang, H., Zettergren, L. D., and Auerbach, R. (1994). In vitro differentiation of $B$ cells and myeloid cells from the early mouse embryo and its extraembryonic yolk sac. Exp. Hematol. 22, 19-25.

Johnson, G. R., and Jones, R. O. (1973). Differentiation of the mammalian hepatic primordium in vitro. I. Morphogenesis and the onset of hematopoiesis. J. Embryol. Exp. Morphol. 30, 83-96.

Johnson, G. R., and Moore, M. A. S. (1975). Role of stem cell migration in initiation of mouse foetal liver haemopoiesis. Nature 258, 726-728. Johnson, G. R., and Barker, D. C. (1985). Erythroid progenitor cells and stimulating factors during murine embryonic and fetal development. Exp. Hematol. 13, 200-208.

Jordan, C. T., and Lemischka, I. R. (1990). Clonal and systemic analysis of long term hematopoiesis in the mouse. Genes Dev. 4, 220-232.
Jordan, C. T., McKearn, J. P., and Lemischka, I. R. (1990). Cellular and developmental properties of fetal hematopoietic stem cells. Cell $61,953-963$.

Keshet, E., Lyman, S. D., Williams, D. E., Anderson, D. M., Jenkins, N. A., Copeland, N. G., and Parada, L. F. (1991). Embryonic RNA expression patterns of the $c$-kit receptor and its cognate ligand suggest multiple functional roles in mouse development. EMBO J. 10, 24252435.

Kollias, G., Wrighton, N., Hurst, J., and Grosveld, F. (1986). Regulated expression of human ${ }^{A} \gamma-, \beta$-and hybrid $\gamma \beta$-globin genes in transgenic mice: manipulation of the developmental expression patterns. Cell 46 , 89-94.

Koopman, P., Gubbay, J., Vivian, N., Goodfellow, P., and LovelfBadge, R. (1991). Male development of chromosomally female mice transgenic for Sry. Nature 351, 117-121.

Lamar, E. E., and Palmer, E. (1984). Y-encoded species-specific DNA in mice: evidence that the $Y$ chromosome exists in two polymorphic forms in inbred strains. Cell $37,171-177$.

Lindenbaum, M. H., and Grosveld, F. (1990). An in vitro globin gene switching model based on differentiated embryonic stem cells. Genes Dev. 4, 2075-2085.

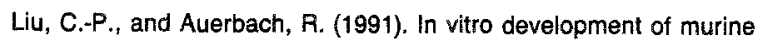
$T$ cells from prethymic and preliver embryonic yolk sac hematopoietic stem cells. Development 113, 1315-1323.

Maeno, M., Tochinai, S., and Katagiri, C. (1985). Differential participation of ventral and dorsolateral mesoderms in the hemopoiesis of Xenopus, as revealed in diploid-triploid or interspecific chimeras. Dev. Biol. $110,503-508$.

Maniatis, T., Fritsch, V., and Sambrook, J. (1982). Molecular Cloning: A Laboratory Manual (Cold Spring Harbor, New York: Cold Spring Habor Laboratory Press).

Matsui, Y., Zsebo, K. M., and Hogan B. L. M. (1990). Embryonic expression of a haematopoietic growth factor encoded by the SL locus and the ligand for c-kit. Nature 347, 667-669.

Medvinsky, A. L. (1993). Ontogeny of the mouse hematopoietic system. Sem. Dev. Biol. 4, 333-340.

Medvinsky, A. L., Samoylina, N. L., Müller, A. M., and Dzierzak, E. A. (1993). An early pre-liver intra-embryonic source of CFU-S in the developing mouse. Nature 364, 64-67.

Micklem, H. S., Ford, C. E., Evans, E. P., and Gray, J. (1966). Interrelationships of myeloid and lymphoid cells studies with chromosomemarked cells transplanted into lethally irradiated mice. Proc. R. Soc. 165,78 .

Moore, M. A. S., and Metcalf, D. (1970). Ontogeny of the haematopoietic system: yolk sac origin of in vivo and in vitro colony forming cells in the developing mouse embryo. Br. J. Haematol. 18, 279-296.

Mülier, A. M., and Dzierzak, E. A. (1993). ES cells have only a limited lymphopoietic potential after adoptive transter into mouse recipients. Development 118, 1343-1351.

Palacios, R., and imhof, B. A. (1993). At day 8-8.5 of mouse development the yolk sac, not the embryo proper, has lymphoid precursor potential in vivo and in vitro. Proc. Natl. Acad. Sci. USA 90, 65816585.

Perah, G., and Feldman, M. (1977). In vitro activation of the in vivo colony-forming units of the mouse yolk sac. J. Cell. Physiol. 97, 193199.

Ogawa, M., Nishikawa, S., Ikuta, K., Yamamura, F., Naito, M., Takahashi, K., and Nishikawa, S.-1. (1988). B cell ontogeny in murine embryo studied by a culture system with the monolayer of a stromal cell clone, ST2: B cell progenitor develops first in the embryonal body rather than in the yolk sac. EMBO J. 7, 1337-1343.

Rusself, E. S. (1979). Hereditary anemias of the mouse: a review for geneticists. Adv. Genet. 20, 357-459.

Russell, E. S., and Bernstein, S. E. (1966). Blood and blood formation. In Biology of the Laboratory Mouse, Second Edition, E. L. Green, ed. (New York: McGraw-Hill), pp. 351-372.

Samoylina, N. L., Gan, O.I., and Medvinsky, A. L. (1990). Development of the hemopoietic system: splenic colony forming units in mouse embryogenesis. Sov. d. Dev. Bioi. 21, 127-133. 
Samoylina, N. L., Medvinsky, A. L., Gan, O. I., and Manakova, T. E. (1992). Hemopoietic stem cells in embryogenesis of the mouse. In Hematology and Blood Transfusion, Volume 35, Modern Trends in Human Leukemia, R. Neth, E. Frolova, R. C. Gallo, M. F. Greaves, B. V. Afanasev, and E. Elstener, eds. (Berlin: Springer), pp. 106-109.

Sonoda, T., Hayashi, C., and Kitamura, Y. (1983). Presence of mast cell precursors in the yolk sac of mice. Dev. Biol. 97, 89-94.

Spangrude, G. J., Heimfeld, S., and Weissman, I. L. (1988). Purification and characterization of mouse hematopoietic stem cells. Science 241, 58-62.

Strouboulis, J., Dillon, N., and Grosveld, F. (1992). Developmental regulation of a complete $70-\mathrm{kb}$ human $\beta$-globin locus in transgenic mice. Genes Dev. 6, 1857-1864.

Symann, M., Anckaert, M. A., Cordier, A., Rodhain, J., and Sokal, G. (1978). Murine yolk sac hematopoiesis studied with the diffusion chamber technique. Exp Hematol. 6, 749-759.

Tavassoli, M. (1994). Embryonic origin of hematopoietic stem cells. Exp. Hemat. 22, 7.

Toles, J. F., Chui, D. H. K., Belbeck, L. W., Starr, E., and Barker, J.E. (1989). Hemopoietic stem cells in murine embryonic yolk sac and peripheral blood. Proc. Natl. Acad. Sci. USA 86, 7456-7459.

Turpen, J. B., Knudson, C. M., and Hoefen, P. S. (1981). The early ontogeny of hematopoietic cells studied by grafting cytogenetically labeled tissue anlagen: localization of a prospective stem cell compartment. Dev. Biol. 85, 99-112.

Weissman, I. L., Baird, S., Gardner, R. L., Papaioannou, V. E., and Raschke, W. (1977). Normal and neoplastic maturation of T-lineage lymphocytes. Cold Spring Harbor Symp. Quant. Biol. 41, 9-21.

Weissman, I., Papaioannou, V., and Gardner, R. (1978). Fetal hematopoietic origins of the adult hematolymphoid system. In Differentiation of Normal and Neoplastic Hematopoietlc Cells (Cold Spring Harbor, New York: Cold Spring Harbor Laboratory Press), pp. 33-47.

Witte, O. N. (1990). Steel locus defines new multipotent growth factor. Cell 63, 5-6.

Wong, P. M. C., Chung, S. W., Chui, D. H. K., and Eaves, C. J. (1986). Properties of the earliest clonogenic hemopoietic precursors to appear in the developing murine yolk sac. Proc. Natl. Acad. Sci. USA 83, 3851-3854. 